\title{
Una nota sobre el desarrollo de las ciencias sociales en América Latina
}

\section{Ricardo Yocelevzky*}

\author{
Perfiles Latinoamericanos | Ensayo \\ vol. 23 | núm. 45 | 2015 \\ pp. 203-222
}

\section{Resumen}

El desarrollo de las ciencias sociales en América Latina desde la segunda posguerra es examinado a través de una periodización que distingue tres paradigmas que han sido dominantes en ese campo: éstos han sido definidos en el contexto de su significación ideológica y su influencia en las políticas aplicadas en los países de la región en el periodo.

\begin{abstract}
The development of Social Sciences in Latin America since the end of the Second World War is examined through a periodization establishing three paradigms considered dominant in each period; these are defined within the context of their ideological relevance and their influence over the policies applied in the Latin American countries during this period.
\end{abstract}

Palabras clave: ciencias sociales, América Latina, desarrollo, dependencia, globalización. Keywords: social sciences, Latin America, development, dependence, globalization.

* Departamento de Política y Cultura, UAM-Xochimilco. 


\section{Introducción}

ara examinar la situación de las ciencias sociales latinoamericanas hoy, especialmente en el ámbito académico, puede ser útil intentar una reconstrucción de la trayectoria de este conjunto de disciplinas a lo largo de la segunda mitad del siglo xx y lo que va del presente siglo.

El propósito de este examen es resaltar las relaciones de mutua determinación entre el conocimiento científico que se construye alrededor de los problemas de la sociedad y los modelos ideológicos dominantes en la práctica de la política en este conjunto de países. Hay que considerar que en este terreno, el de las ideas, la modernización de Europa Occidental agregó al pensamiento religioso, sin reemplazarlo más que en ciertos ámbitos, el pensamiento científico y las doctrinas políticas seculares.

No se trata de distinguir entre prácticas científica e ideológica, como si hubiera una diferencia de naturaleza entre ambas, sino más bien de examinar las relaciones que la evolución conjunta de ambas permite hacer visible.

Con este propósito se describe a continuación la evolución de los modelos dominantes en la investigación y la docencia de ciencias sociales y, en paralelo, algunos rasgos de las políticas que han caracterizado la acción de los estados latinoamericanos en un sentido estratégico, buscando poner de relieve las relaciones entre ambos fenómenos del mundo ideológico.

Con este fin, se propone organizar el examen a través de la construcción de tres "paradigmas", considerados dominantes en el periodo en referencia. Esto requiere de una breve justificación del uso del término paradigma y una precisión acerca de las limitaciones del sentido con que es introducido aquí.

El término paradigma debe su popularidad a su aparición como concepto clave de la obra de Thomas Kuhn La estructura de las revoluciones cientificas, publicada por primera vez en $1962 .{ }^{1}$ La multiplicidad de sentidos en que es usado en esa obra ha sido parte de la crítica a que ha sido sometida desde el primer simposio dedicado a su discusión. ${ }^{2}$ Sin embargo, al margen de las consecuencias de esas discusiones, en ámbitos relacionados pero distintos como son la epistemología y la historia de la ciencia, la noción de paradigma ha pasado al uso de sentido común científico con un significado que busca caracterizar un

The University of Chicago Press.

I. Lakatos, y A. Musgrave (eds.), 1975, La critica y el desarrollo del conocimiento. Actas del Coloquio Internacional de Filosofia de la Ciencia, celebrado en Londres en 1965, Barcelona, Ediciones Grijalbo. Allí se encuentra el artículo de Margaret Masterman "La naturaleza de los paradigmas", en el cual se establecen y documentan los muchos sentidos en los que Kuhn utiliza el término. 
complejo de conocimiento o prácticas propios de una época y de un ámbito de acción particular. Aun cuando éste parezca ser el sentido más laxo, resulta de utilidad para realizar la necesaria operación de periodizar que se requiere en el análisis propuesto aquí.

En este punto se impone la necesidad de relativizar también el término "dominante". Se entenderá aquí como tal a un constructo teórico que articula el qué hacer de las disciplinas de ciencias sociales alrededor de ideas que orientan la adopción de teorías sustantivas dentro de cada una de ellas, constituyendo así un verdadero "filtro" para la integración en el contexto latinoamericano de las discusiones, avances y "modas" vigentes para las ciencias sociales en los lugares de referencia académica y política, principalmente los Estados Unidos de Norteamérica y Europa Occidental.

La expresión empírica de esta dominación está en los planes y programas de estudios de las escuelas de formación profesional de las disciplinas de ciencias sociales, así como en las orientaciones favorecidas de la investigación y el desempeño profesional de los egresados de ellas. Esto en ningún caso significa monopolio ideológico del paradigma dominante, puesto que en todo momento existen científicos sociales o centros y escuelas con orientaciones alternativas o que simplemente ignoran del todo al paradigma y desarrollan sus actividades atendiendo sólo a los desarrollos disciplinarios en los centros que adoptan como referencia. ${ }^{3}$

Por todo lo anterior, es necesario especificar los componentes o dimensiones de cada uno de los paradigmas que serán considerados para los fines de comparación entre los periodos, aun cuando el tema de la conmensurabilidad o inconmensurabilidad de los paradigmas ha sido objeto de la producción de una amplia bibliografía que se ocupó principalmente de los problemas epistemológicos involucrados en la polisemia del término. El restringir mi construcción de paradigma a ciertos aspectos teóricos, ideológicos y político-estratégicos, es posible dado que los aspectos metodológicos, técnicos y sus implicaciones lógicas y epistemológicas son tratados en esta ocasión por Fernando Cortés. ${ }^{4}$

La primera característica que se definirá para cada paradigma es el título, nombre que lo caracteriza y también denomina, en algunos casos, al periodo

3 Para cada disciplina la vigencia del paradigma es diferente, como habrá que señalarlo en algunos casos. En general, la ciencia política es menos ligada a las cuestiones latinoamericanas que la sociología. Un ejemplo sobresaliente de independencia respecto de lo que se expone aquí como "paradigma dominante" en algún periodo fue la Escuela de Economía de la Pontificia Universidad Católica de Chile, cuna de los llamados "Chicago boys" y centro de propagación de un paradigma dominante en un periodo posterior.

4 Una versión previa de esta exposición fue preparada para la mesa redonda inaugural del Congreso Latinoamericano de Estudiantes de Postgrado en Ciencias Sociales (CLEPSO) organizado por los estudiantes de la Sede Académica de México de la Flacso, realizada el 26 de junio de 2014. 
en el cual el mismo es considerado dominante. De este modo definimos tres periodos denominados según el paradigma que consideramos dominante en cada uno de ellos: desarrollismo, desde fines de la década de los cuarenta hasta mediados de los ańos sesenta; dependentismo, desde mediados de los sesenta hasta la instauración de las dictaduras sudamericanas (1973-1976); neoliberalismo, en ascenso desde fines de los setenta, con culminación de su imposición en la crisis de la deuda en la primera mitad de la década de los ochenta, y vigente hasta el presente.

Evidentemente, el uso de estas denominaciones es bastante impreciso y por ello es que su contenido debe ser aclarado por las características de cada periodo que consideramos como dimensiones del paradigma, la primera de las cuales tiene el rango de concepto central o articulador de la influencia del paradigma en cada una de las disciplinas de ciencias sociales, llegando en algunos casos a definir una especialidad o subdisciplina. Éstos son, para cada caso, las nociones de "desarrollo", "dependencia" y "globalización".

Estos conceptos determinan en su funcionamiento como instrumentos teóricos, claves de comprensión del contexto general en que construyen sus objetos los investigadores, las relaciones entre las distintas disciplinas, las cuales constituyen una tercera dimensión de comparación. No hay que olvidar que cada disciplina de ciencias sociales se constituye, profesionaliza e institucionaliza a partir de un "recorte" en una "realidad" que, por su parte, no diferencia ámbitos ni de conocimiento ni de acción, por lo que todos los recortes disciplinarios son productos de construcciones conceptuales.

Si bien el origen de las ideas centrales para cada paradigma es identificable dentro de una disciplina particular, la difusión y ascenso a la posición dominante están vinculados a la adopción, recepción o adaptación del trabajo de las demás disciplinas a estas estructuras conceptuales que funcionan como eje de cada uno de ellos. En general, sin disponer de una clasificación precisa, es posible distinguir como tendencia característica de cada paradigma el impulso hacia el trabajo interdisciplinario o el aislamiento y subordinación de las disciplinas.

Las dos dimensiones restantes permiten vincular a estos paradigmas con la lucha ideológica más amplia en las sociedades latinoamericanas. Esto es, la lucha por la constitución del "sentido común" en todos los niveles y expresiones. La primera de ellas es el contenido programático, más o menos explícito en el contenido teórico del paradigma. Éste realiza la vinculación política más importante al tratar de influir en las visiones de los políticos profesionales, tanto en el gobierno como en la oposición.

La última dimensión de comparación es un producto de conocimiento que intenta dos cosas al menos: primero, recuperar la complejidad de la realidad 
"nacional" fragmentada por los enfoques disciplinarios y, buscando este objetivo, ofrecer una revisión de la historia nacional a través de una periodización fundamentada en un esquema interpretativo generado por los conceptos centrales del paradigma.

En estas cinco dimensiones se busca a continuación organizar la exposición del desarrollo de las ciencias sociales latinoamericanas y su relación con las luchas ideológicas en las que se han expresado y resuelto las contradicciones y conflictos de estas sociedades en los últimos sesenta o setenta ańos. Toda la exposición sufre de la natural refracción que produce el rastreo intencionado por la búsqueda de la génesis de la situación actual.

\section{El desarrollismo}

Este pensamiento predominó durante el periodo de inauguración de dos procesos centrales en nuestra preocupación: la profesionalización e institucionalización de la producción, difusión y aplicación del conocimiento de las ciencias sociales en los países de la América Latina. Sobre el contenido ideológico de los planteamientos desarrollistas es importante registrar que reemplazan a las nociones de "atraso" e "inferioridad", planteamientos que constituían la visión del lugar que los países latinoamericanos ocupaban en un mundo que había tomado el tren del progreso cuya locomotora se ubicaba primero en Europa Occidental y que en el siglo xx se estaba trasladando a los Estados Unidos de Norteamérica.

Lo novedoso del nuevo planteamiento era que se fundamentaba en una teoría en el campo de las ciencias sociales. La idea principal era que mientras unos países se desarrollaban otros se rezagaban, por lo que la idea de ir unos delante de otros en la misma dirección era cuestionada porque el aumento de la brecha entre unos y otros llegaba a constituir una dirección distinta en la medida en que el subdesarrollo aumentaba. Esto permitía definir una tipología de países de acuerdo al lugar que ocupaban en el comercio internacional: países centrales, caracterizados por la exportación de manufacturas y bienes industriales, y países periféricos, exportadores de alimentos y materias primas.

La teoría convencional del comercio internacional sostenía que el intercambio entre estos dos tipos de países distribuiría los beneficios del progreso técnico que representaba la industrialización, sin importar donde tuviera lugar éste. La tesis central del desarrollismo cuestiona tanto teórica como empíricamente estas afirmaciones, enfocándose en la diferencia del dinamismo de los precios de las exportaciones de los dos tipos de países, el cual determina un deterioro de los términos de intercambio en perjuicio de los países periféricos. 
Este planteamiento da lugar a una estrategia de solución a los problemas del desarrollo de los países de la América Latina que consiste en industrializar esas economías como manera de retener en esta periferia una parte de los beneficios del progreso técnico, que sería, por necesidad, creciente en la medida en que estas economías se desarrollaran, es decir, no sólo crecieran sino que cambiaran su carácter al construir un sector industrial que hiciera más compleja toda la sociedad.

Este último punto generaba la expansión del planteamiento teórico de los economistas hasta involucrar a más de un enfoque sociológico e interpelar a los demógrafos, geógrafos e historiadores. Desde el punto de vista de la sociología, una ciencia que como carrera aparecía como novedad en las universidades de América Latina en la década de 1950, la teoría de la modernización aparecía como un esquema que permitía comprender e interpretar los fenómenos que empíricamente aparecían como más notables, la migración del campo a la ciudad, por ejemplo, que planteó los problemas de investigación más visitados por demógrafos, sociólogos e, incluso, cientistas políticos.

En una primera mirada, lo que más llamaba la atención era la velocidad de los cambios observables, la llegada de migrantes a las ciudades, principalmente a las capitales de cada país, y la constitución de asentamientos periféricos habitados por seres humanos marginales, en los varios sentidos que se intentó teorizar su situación. Los intentos de conceptualización de estas masas como actores sociales, colectivos, tenían muy claramente especificado un punto de partida político. Tal como había ocurrido después de la revolución francesa, se concebía a este conjunto como "clases peligrosas", especialmente después de los acontecimientos de 1948 en Bogotá (el llamado "Bogotazo"). Los orígenes de los migrantes variaban de un país a otro, lo cual planteaba problemas que requerían una consideración histórica que diera cuenta de la especificidad de la composición de las poblaciones objeto de estas discusiones.

En el contexto de la "guerra fría", la preocupación desde la perspectiva conservadora era evitar la penetración de la ideología marxista, en tanto entre los marxistas el problema era encontrar entre estos sectores populares una clase obrera que asumiera su papel histórico de vanguardia en una eventual evolución socialista. Dada la condición migrante más o menos reciente, la discusión se trasladaba al potencial organizacional e ideológico que pudiera orientar los cambios que ocurrían inevitablemente.

En retrospectiva, es posible decir que el camino asumido fue el de una alianza social que en cada país se adaptó a las composiciones históricas que determinaron el modelo de organización y de ideología política que canalizó, orientó y controló las varias formas y grados de incorporación de estas masas a la participación política. En general, la ideología adoptada fue la del "desarrollo 
nacional", centrada en el eje de la industrialización como motor del cambio social y solución a los problemas que estas transformaciones planteaban. Esto permitía usar la visión "técnica" que se desprendía de la acción de las Naciones Unidas y, en particular de la Comisión Económica para América Latina (CEPAL). Este consenso técnico permitió, por una parte, las formas nacionales de adaptación, siendo la más notable el llamado, en esa época, "populismo latinoamericano", representado quizás más que en cualquiera otra expresión por el peronismo en Argentina y el varguismo (de Getulio Vargas) en Brasil. Otras formas fueron la maduración del modelo de partido de Estado en México, bajo Lázaro Cárdenas, y el modelo de alianzas de partidos (un Frente Popular sui generis) en Chile.

Lo común a estas formas político-ideológicas que adoptaban un proyecto industrializador eran las ideas de planeación del desarrollo que implicaban la acción del Estado en la definición de las cuestiones económicas estratégicas. Esto era concebido como una cuestión "técnica", en la que se abría la posibilidad de colaboración de los organismos internacionales (como la misma CEPAL) con los gobiernos de la región sin importar las definiciones ideológicas o político partidistas. Sin embargo, la difusión de las ideas producidas en la CEPAL era una preocupación formal, que se traducía en la invitación a la discusión de los informes del organismo, de políticos no sólo de gobierno sino también de oposición, entre los cuales las ideas desarrollistas llegaron a ser parte de sus programas.

Por otra parte, el marxismo oficial, representado por los partidos comunistas, tenía importancia variable en los países latinoamericanos. Sin embargo, su visión de la situación de estos países se orientaba por la idea de atraso, en el sentido de representar situaciones de colonialismo o semicolonialismo, con supervivencias de un régimen feudal en el sector rural. De este modo, el apoyo a planes de desarrollo nacional, inspirados en las ideas desarrollistas, era coherente con la aspiración a un desarrollo capitalista "nacional", antiimperialista, que, eventualmente, pusiera a cada país en situación de contar con una clase obrera, protagonista de la futura revolución socialista. Implícito al comienzo, y luego no tanto, estaba el supuesto del carácter nacional de los intereses de la burguesía.

Estas coincidencias son importantes en dos sentidos al menos. En primer lugar, expresan ideológicamente la amplitud de la alianza social que en cada país es el sustrato de la política de desarrollo y, al mismo tiempo, en el contexto de la guerra fría, asegura estabilidad en la región latinoamericana. La estabilidad, como característica de los sistemas políticos es más valorada que la democracia. Sin embargo, a fines de la década de los cincuenta, se produce una ola de desestabilización que resulta en una relativa democratización y 
también en cambios inesperados. La caída de Rojas Pinilla en Colombia, de Pérez Jiménez en Venezuela, de Batista en Cuba y el asesinato de Trujillo en República Dominicana, todo ocurrido entre 1957 y 1961, tuvieron como resultado más inesperado la evolución de la revolución cubana hacia el socialismo.

El impacto de la revolución cubana en toda América Latina, en particular en la evolución ideológica y, finalmente, en las ciencias sociales, no puede ser exagerado. Cuatro campos fueron afectados profundamente: el político, el militar, el ideológico y, lo que nos interesa más directamente aquí, las ciencias sociales. El modelo político-militar de la revolución cubana tuvo un impacto que hasta el día de hoy permanece simbólicamente en la imagen de Ernesto "Che" Guevara. La estrategia de guerrillas, y su teorización por parte del mismo Che Guevara, se difundieron de tal manera que todos los países de América Latina, con la única excepción de Costa Rica, tuvieron algún movimiento político-militar de tipo guerrillero en la década siguiente al triunfo de la guerrilla cubana.

En el campo de la política las consecuencias fueron múltiples, afectando a todos los actores en los países de la región. Comenzando por el terreno internacional, en el contexto de la guerra fría, la adhesión de Cuba al campo socialista y el apoyo dado por éste, especialmente por la Unión Soviética, desbalanceó el equilibrio establecido en la segunda posguerra. La posición geográfica de la isla de Cuba significó una renegociación del pacto que distribuía el mundo en zonas de influencia. En América Latina, zona de influencia de los Estados Unidos de Norteamérica, la presencia de movimientos que, en conjunto llegaron a ser conocidos como "castristas" introdujo la necesidad de revisar las relaciones entre el gobierno de Estados Unidos y los gobiernos de la región.

El gobierno de los Estados Unidos enfrentó la nueva situación haciendo cambios en su política exterior hacia América Latina en los cuatro aspectos señalados: en el plano político aisló a Cuba haciéndola expulsar de la Organización de Estados Americanos (OEA). En el terreno militar redefinió los condicionamientos para el acceso a la ayuda de los Estados Unidos a las fuerzas armadas de los países latinoamericanos, en el sentido de reorientar sus estructuras hacia el combate de un enemigo interno, encarnado en las guerrillas castristas que aparecían por todas partes. En el plano de la política de desarrollo promovió un programa, publicitado como Alianza para el Progreso, en el que el acceso a los fondos que el gobierno estadounidense proporcionaría se condicionaba a la realización de algunas "reformas estructurales". Estas últimas formaban parte de un paquete fuertemente inspirado en las ideas desarrollistas generadas en la CEPAL. Por último, se diseñó un programa de investigación sociocultural destinado a evaluar las posibilidades de una repetición de la experiencia cubana estableciendo la situación ideológica de las sociedades latinoamericanas. Éste fue 
el poco recordado hoy Proyecto Camelot, denunciado en su momento tanto por científicos sociales en América Latina como en Estados Unidos. Todo esto influyó tarde o temprano en las características que fue asumiendo la enseñanza y la investigación en ciencias sociales en América Latina.

Puede parecer paradojal que cuando las ideas desarrollistas son adoptadas por los centros de poder más importantes es cuando aparecen alternativas más radicales tanto políticas como ideológicas. Es un hecho poco reconocido el que la significación de la revolución cubana contiene una ambigüedad, en el sentido de que su identificación con el campo socialista y las ideas marxistas va asociada a su contenido de "modelo alternativo de desarrollo". La explicación de las contradicciones que la revolución cubana planteaba en todos los campos fue el estímulo para el desarrollo y difusión de las teorías de la dependencia, que buscaban estructurar el paradigma alternativo al desarrollismo.

\section{El dependentismo}

Las teorías de la dependencia fueron respuestas plurales a preguntas diversas que surgieron en gran parte como consecuencia de la revolución cubana. Al aparecer la revolución cubana como una alternativa política a la vía de desarrollo en la que se encontraban empeñados la mayoría de los países de la región, las críticas a los resultados de la aplicación de esa política de desarrollo (centrada en la industrialización sustitutiva) se conectaban de varias maneras con la conclusión común de la vigencia de una alternativa revolucionaria. La misma respuesta de Estados Unidos, la Alianza para el Progreso, indicaba la necesidad de una acción política más decidida (reformas estructurales) que permitiera acelerar un proceso estancado, o de velocidad y profundidad insuficientes, debido a resistencias "estructurales". Para los críticos de diversos grados de escepticismo respecto de las posibilidades del desarrollo de estos países, el diagnóstico conducía desde la necesidad de un reformismo profundo hasta la urgencia de la revolución. La profundidad del cambio de velocidad que se necesitaba parecía indicado por el uso publicitario del término "revolución”. La alternativa a la revolución cubana que contó con la bendición y el apoyo de los Estados Unidos fue la "Revolución en libertad" de la Democracia Cristiana chilena (1964-1970).

Que Cuba se declarara socialista planteaba un problema al marxismo oficial debido a la contradicción con la tesis de la necesidad de cumplir con una etapa de desarrollo capitalista independiente, necesariamente previa a la revolución socialista, debido a las supervivencias feudales observables en los países coloniales y semicoloniales. Al modelo exitoso de acción político-militar de la 
guerrilla cubana le faltaba una fundamentación teórica que justificara la aplicación inmediata de un programa sedicentemente "socialista". En esta discusión fueron cruciales las aportaciones de André Gunder Frank. No sólo afirmaba él que América Latina no era "feudal", tesis ya sostenida por algunos historiadores, entre ellos algunos trotskistas, sino que mostraba que las zonas de mayor "atraso" aparente, como Zacatecas en México y el norte del Brasil, eran lugares donde la pobreza observable era el resultado de una prosperidad anterior, resultado de ser estas las regiones desde donde se exportaba aquellos productos que hacían la conexión principal entre esos países y el mercado mundial, la plata en México y el caucho en Brasil. Una historia semejante a la del caucho en Brasil es la del salitre (nitratos) en Chile. Para Frank, la consecuencia de todo esto era que el desarrollo de los países latinoamericanos no se lograría integrándose a la economía capitalista sino, por el contrario, separándose de ella.

Esta propuesta programática, separarse del mercado mundial capitalista, ponía en primer plano la crítica a las propuestas del desarrollismo, industrialización sustitutiva de importaciones y defensa de los precios de las materias primas exportadas por los países de América Latina. Esta estrategia de desarrollo constituía un programa reformista, gradual, que se pasó a considerar no sólo fracasado en su aplicación sino condenado fatalmente al fracaso por los análisis que dentro del enfoque de la dependencia retomaron la misma discusión desde otros ángulos.

El conflicto entre las dos visiones se expresó en todos los ámbitos de lucha ideológica, siendo el más visible en la izquierda el conflicto entre "nueva izquierda" (castrista) y los partidos comunistas, una vieja izquierda. Reforma o revolución eran los términos de una alternativa que parecía realista, dado el ascenso de las fuerzas que representaban un desarrollismo triunfante (al ser no sólo tolerado sino promovido por los Estados Unidos de Norteamérica) y una generación de (sobre todo) estudiantes universitarios que se autopercibían como una élite de reemplazo de los viejos políticos centristas, nacionalistas, desarrollistas, cuyas expresiones políticas eran la socialdemocracia y, en América Latina, la Democracia Cristiana.

Al coincidir con el crecimiento de la matrícula universitaria, estos conflictos ideológicos se expresaron con particular agudeza en las escuelas y facultades de ciencias sociales, muchas de ellas, en aquel momento, de creación relativamente reciente. El conflicto se centraba en los planes y programas de estudio de las carreras de ciencias sociales. En particular se trataba de la incorporación del marxismo a la enseñanza de teorías sociales, campo en el que la particular versión de Louis Althusser del pensamiento de Marx llegó a ser dominante en muchas escuelas. Por otra parte, se trataba de no producir un conocimiento que pudiera ser instrumentalizado por las fuerzas de la dominación imperialista, lo cual ya había sido ejemplificado en el llamado Proyecto Camelot. 
La investigación de las formas y mecanismos de la dependencia se constituyó en el eje, alrededor del cual se produjo una variedad de construcciones teóricas. Por una parte, los cambios que las empresas capitalistas de los países centrales habían experimentado durante la expansión económica de la posguerra habían determinado que los mecanismos de protección y estímulo a la industrialización periférica resultaran en muchos casos ineficaces o, incluso, se usaran en beneficio del capital extranjero, al instalarse en los países de la región empresas subsidiarias de transnacionales, ya fuera como inversión nueva o adquiriendo y subordinando plantas industriales nacionales. Esta estructura afectaba de una manera nueva, ya no eran los "enclaves" tradicionales sino la industria la que se desarrollaba en función de intereses ajenos. La definición de los mecanismos de traslado de "excedente económico" era a la vez que un resultado de investigación una denuncia.

Las transformaciones de los países latinoamericanos de las décadas de los cincuenta y sesenta no parecían cambiar sus estructuras en un sentido que los acercara al desarrollo sino que, al ser subordinada a las estrategias del capital transnacional, deformaban las estructuras de estas economías en un nuevo sentido. Los análisis de estas evoluciones podían o no estar orientados al programa de una revolución, pero sí planteaban el problema de los actores sociales, las clases, que emergían en estas estructuras de desarrollo capitalista no original en las cuales el análisis se hacía con conceptos construidos en los países de desarrollo original (Europa).

Las teorías desarrollistas habían dado lugar a una periodización de la historia económica de América Latina que distinguía un periodo de "crecimiento hacia fuera" (el descrito como crítica de la teoría convencional del comercio internacional) y uno, actual en los años de formulación de la teoría del desarrollo, de "crecimiento hacia dentro", cuyo eje era el proceso de industrialización. La teoría de la dependencia formulada por Fernando Henrique Cardoso y Enzo Faletto, definía una tipología de situaciones de los países latinoamericanos a partir de la propiedad y/o el control del producto de exportación que hacía la conexión principal de cada país con el mercado mundial, distinguiendo entre los que exportaban algo que era controlado por una clase o sector de clase "nacional”, es decir, del país, y aquellas economías de "enclave", en las que el principal producto de exportación era directamente controlado por el capital extranjero. Como ejemplos típicos de cada situación se puede pensar en Argentina y Chile y las diferencias de estructuras y procesos políticos a partir del papel del Estado y las clases dominantes en cada caso.

De cualquier manera, sea desde una visión de raíz "weberiana" (como la de Cardoso y Faletto) o desde una visión marxista, como la mayoría de los teóricos de la dependencia, el problema central era definir las clases sociales que, como 
actores colectivos, definirían el futuro de los países latinoamericanos, fuera para liderar una revolución socialista o para dirigir una proceso de desarrollo modernizador centrado en la industrialización.

Que las clases sociales eran el punto crucial a resolver teóricamente queda claro al recordar dos eventos académicos de gran relevancia, ambos ocurridos en México. El primero en Mérida, en diciembre de 1971, y el segundo en Oaxaca, en junio de1973. Estos dos seminarios representan una muestra del grado de desarrollo alcanzado por las ciencias sociales en América Latina y su conexión con desarrollos que tenían lugar en otros lugares del mundo, particularmente en Francia. ${ }^{5}$

La discusión sobre las clases sociales se centraba en las perspectivas de análisis posibles de los actores colectivos presentes y distinguibles empíricamente en los procesos de cambio observados en los países latinoamericanos. Para la teoría marxista se trataba de explicar la vigencia de la revolución socialista en países con débil presencia de proletariado industrial, a pesar de que ya Cuba llevaba más de diez años de declararse socialista y que en Chile ya había sobrevivido más de dos años un gobierno que se proponía comenzar un proceso que conduciría, eventualmente, a la construcción del socialismo. Para la teoría de la modernización, el problema era justificar el papel de diversos actores agrupados en la denominación "clases medias". En ambos casos se hablaba de "revolución". En uno, la modernización implicaba una "revolución burguesa”, que en América Latina adolecía de un déficit democrático, y para la discusión entre marxistas el problema era la viabilidad de una "revolución socialista".

Las coincidencias prácticas en cuanto a las reformas necesarias hacían que la discusión se redujera a cuestiones de profundidad y velocidad en la aplicación de las mismas. La ambigüedad de las relaciones entre las dos visiones dominantes en las ciencias sociales latinoamericanas y las prácticas de políticas de desarrollo quedaron más a la vista que nunca durante el segundo intento de transformación con un sentido socialista, el realizado en Chile por el gobierno de Salvador Allende entre 1970 y 1973. Por una parte, el programa económico de la Unidad Popular y su aplicación tuvieron como autores y actores a economistas formados en el pensamiento de la CEPAL y las discusiones posteriores que se han descrito aquí, lo cual implicaba diversos grados de radicalismo en las propuestas, mientras que las determinaciones del contexto

5 Las publicaciones de ambos seminarios son: del seminario de Mérida, Yucatán, R. Benítez Zenteno (coord.), 1973, Las clases sociales en América Latina. Problemas de conceptualización, México, IIs-unam/ Siglo xxi Editores; y del seminario de Oaxaca, R. Benítez Zenteno (coord.), 1978, Clases sociales y crisis politica en América Latina, México, IIS-UNAM/Siglo XXI Editores. De los no latinoamericanos participantes en ambos eventos, todos estaban asociados a universidades de Francia o Bélgica. 
político nacional — las particularidades del sistema político chileno existente hasta 1973 - modulaba las propuestas en el sentido de no representar una programa de revolución socialista, pero no podía evitar ubicarse como punto de partida de un proceso cuyo horizonte era la construcción de una sociedad distinta, no sólo el desarrollo económico del país existente realmente.

Este carácter revolucionario fue certificado por una larga visita a Chile de Fidel Castro en 1971, primer año del gobierno de la Unidad Popular. Durante esta visita se produjo una reunión de Fidel Castro y Raúl Prebisch en la cual aparece como punto de acuerdo entre las dos visiones los logros en el terreno social de la revolución cubana. La situación descrita por un testigo presencial revela, a pesar de lo que se pueda atribuir a lo ceremonial de la ocasión, las coincidencias entre dos actores que nunca habían aparecido coincidiendo en nada.

Figurativamente, el desarrollismo latinoamericano alcanzó su cenit el 29 de noviembre de 1971, cuando en el hermoso e imponente auditorio de la sede de CEPAL en Santiago, el gran economista argentino Raúl Prebisch, ofreció la tribuna al Presidente Fidel Castro, a la sazón de visita en Chile invitado por el gobierno de Salvador Allende. Ante un auditorio que reunía a lo más granado de la intelectualidad latinoamericana, autoridades de Naciones Unidas y el gobierno chileno, y a todo el cuerpo diplomático, Fidel pronunció un discurso notable en el que repasó la manera como Cuba revolucionaria había ido cumpliendo el programa de CEPAL. Tras cada uno de sus asertos referidos a nutrición, salud, educación, industrialización, energía, etc., así como un alegato ferviente a favor de la integración regional, Fidel pedía la aprobación de Prebisch, sentado a su lado. ¿¿No es verdad, doctor Prebisch? — preguntaba Fidel en cada ocasión — ¡Así es, señor Presidente! —asentía el insigne fundador de CEPAL y principal inspirador de esta estrategia. ${ }^{6}$

Lo paradojal de la escena descrita radica en la aparente coincidencia de dos políticas de desarrollo social cuyos fundamentos eran los contendientes en el campo de las ciencias sociales y en la política: desarrollismo vs. dependentismo y reforma vs. revolución. La revolución cubana nunca había contado con la menor simpatía por parte de Prebisch. Finalmente, quien iba a juntar ambas visiones en un sólo paquete era su enemigo ideológico y reemplazante en la hegemonía en el mundo ideológico de las ciencias sociales, la economía neoclásica en su versión monetarista predicada por Milton Friedman desde la Universidad de Chicago.

6 M. Riesco (2008). "Allende, un chileno universal”, en H. Soto, y M. Lawner (edits.), Salvador Allende, presencia en la ausencia, Santiago de Chile, Lom Editores.

Perfiles Latinoamericanos | vol. 23, núm. 45, enero-junio de 2015 | Flacso México Ricardo Yocelevzky | Una nota sobre el desarrollo de las ciencias sociales en América Latina | pp. 203-222 


\section{El neoliberalismo}

Designado de esta manera el paradigma dominante desde las últimas décadas del siglo xx, en América Latina apareció como una confrontación ideológica en el seno de las fuerzas que apoyaron a la dictadura de Augusto Pinochet en Chile. Más que las particularidades del proceso político, es importante observar las características de los cambios ideológicos.

La orientación teórica centrada en la visión elaborada y difundida desde la Universidad de Chicago estaba asociada a una organización de lucha ideológica a nivel internacional, la Fundación Monte Peregrino "Mont Pelerin", cuyo enemigo definido no era sólo el comunismo sino toda forma de intervención del Estado en la economía, particularmente el Estado benefactor, y su fundamento en la ciencia económica: el estructuralismo. Como lo expresaron los economistas asociados a la dictadura en los años ochenta:

[...] en el plano de las ideas, la acción desarrollada en torno al diario El Mercurio fue de una importancia determinante. Este matutino inició en la segunda mitad de los años sesenta una notable campaña de difusión de la moderna ciencia económica y de defensa de la economía privada y libre que contrastó fuertemente con el intervencionismo ambiente. ${ }^{7}$

En las condiciones que se crearon en Chile con el golpe de estado de 1973, se desplegaron todas las características de esta visión, sin trabas políticas ni ideológicas a partir de 1975. Esto permitió ver un sectarismo simétrico al del marxismo académico de los años sesenta, la oposición entre ciencia e ideología en la que, obviamente, se reserva la exclusividad de la autoridad de la ciencia para sí, condenando a toda otra forma de conocimiento en el mismo campo como ideología.

Sin embargo, la misma asociación con una dictadura tan repugnante, que les proporcionaba una posibilidad de aplicación de sus ideas y programas sin obstrucciones mayores desde los procesos políticos, implicaba una limitación para la expansión de su influencia fuera de ese país.

La crisis de la deuda externa de América Latina en 1982 fue la coyuntura que permitió la expansión en la práctica de un modelo que en teoría iba ganando adeptos, pero que en el campo político era impulsado por tecnócratas que accedían al poder paulatinamente. Los condicionamientos de los organismos financieros internacionales (Fondo Monetario y Banco Mundial) impusieron

7 Á. Bardón M., C. Carrasco, y Á. Vial G., 1985, Una década de cambios económicos. La experiencia chilena 1973-1983, Santiago, Editorial Andrés Bello, p. 3. 
a los estados nacionales deudores de América Latina la tarea de impedir que el sistema financiero internacional dejara de funcionar.

Esto significó dejar en evidencia que la tarea central de cualquier política económica nacional consiste en adaptarse a la condición dominante del mundo actual, la "globalización". Las formas y términos de esas adaptaciones nacionales están determinadas por las ventajas competitivas, concepto que reemplaza a las ventajas comparativas de la economía clásica.

A fines de la década de los ochenta, la condición de dominante del nuevo paradigma parece bien establecida: un verdadero manifiesto es el documento elaborado para el Banco Mundial por Rudiger Dornbusch y Sebastián Edwards, publicado en $1989,{ }^{8}$ el cual redefine dentro de la teoría económica prevaleciente el término populismo, agregando a su sentido peyorativo la significación económica que lo asocia con cualquier política de intención redistributiva. En 1990, la revista Newsweek proclamaba que "10,000 hombres de Harvard. Una nueva generación de tecnócratas entrenados en los Estados Unidos están reestructurando la economías de América Latina". ${ }^{9}$ El mismo artículo describía el entorno mundial: "[...] el socialismo y el paternalismo económicos están sitiados; viva [en castellano en el original] la economía de mercado. En América Latina, líderes democráticos han asumido el poder desde Tijuana hasta Tierra del Fuego en los últimos cinco años".

Todos estos cambios son, en parte, un reflejo y consecuencia de los experimentados por el mundo en el mismo periodo. El conjunto de transformaciones que acarrea el fin del ciclo de expansión económica iniciado después de la Segunda Guerra Mundial, en el terreno institucional con el fin de la estabilidad de los sistemas monetarios a partir de la devaluación del dólar en 1971, el alza de los precios del petróleo a partir de 1973, la democratización de la política en América Latina en los ochenta y, finalmente, la caída del muro de Berlín, la disolución de la Unión Soviética y del campo de países socialistas que constituían su zona de influencia. Todo este proceso, en balance, puede ser caracterizado como el triunfo del liberalismo económico, pero también político, en secuencias y combinaciones propias de cada proceso nacional. Esto es lo que justifica llamar "neoliberalismo" al paradigma dominante.

Esta descripción pone de relieve algunas características del nuevo paradigma y su ascenso a la posición dominante:

Primero, a diferencia de los otros dos paradigmas descritos más arriba, la dominación en el mundo académico de este tercero siguió, en América Latina,

8 The Macroeconomics of Populism in Latin America, 1989, diciembre, Working Paper núm. 316, Country Economics Department, The World Bank.

9 Newsweek, 1990, 10 de diciembre, pp. 20-22.

Perfiles Latinoamericanos | vol. 23, núm. 45, enero-junio de 2015 | Flacso México Ricardo Yocelevzky | Una nota sobre el desarrollo de las ciencias sociales en América Latina | pp. 203-222 
al triunfo y aplicación de sus prescripciones en el ámbito del poder político. El reemplazo en las élites políticas y en los mandos de las economías nacionales de los egresados de universidades públicas y estatales por cuadros provenientes de universidades privadas o, al menos, con estudios de posgrado en el extranjero, precedió a la dominación de sus ideas en el ámbito académico, las cuales todavía enfrentan focos de resistencia crítica en algunas universidades públicas de los países de la región. Sin embargo, incluso esta resistencia se da en los términos de la polémica definidos por el paradigma "neoliberal", es decir, consiste en dos planteamientos básicos: una reivindicación histórica de la economía estructuralista latinoamericana, y los logros en el desarrollo nacional de las políticas inspiradas por ella en las décadas de los cincuenta y los sesenta; y, en segundo lugar, en la denuncia de las consecuencias sociales y políticas de la aplicación de las políticas de adaptación a la globalización.

Una segunda diferencia, central para las ciencias sociales, es la relación que entre ellas se desarrolla como consecuencia de la dominación de cada paradigma. Si bien el desarrollismo surge de una visión de los efectos del comercio internacional en las economías nacionales, la noción de desarrollo, en sí misma, involucra en grados variables, pero crecientemente, a las otras disciplinas. Así, la sociología, la demografía y la antropología se ven redefinidas por las ideas desarrollistas. En todas ellas se escenifica el enfrentamiento entre desarrollistas y dependentistas, cuando para estos últimos la definición de estrategias para la revolución pone en primer plano a la sociología y a la ciencia política.

Los años de la derrota política de la izquierda en América Latina, entre las décadas de 1970 y 1980, producen una transformación en los problemas y los enfoques de las distintas disciplinas de las ciencias sociales, los cuales en mayor o menor medida están asociados a la dominación de la economía neoclásica.

La concepción de ciencia de los economistas de Chicago y sus discípulos latinoamericanos elimina la necesidad de considerar las diferencias y particularidades históricas de cada país, en el sentido de que las teorías y modelos económicos en los que se basan sus propuestas de política son supuestos como generales (o, incluso, universales). La subordinación del conocimiento a la reproducción de la sociedad con sus características actuales se expresa, entre muchos otros síntomas, en la naturalidad con que se toma la decisión de transformar las facultades de economía en escuelas de "negocios".

Hay excepciones, pero en general, la relación de los economistas con la sociología y la ciencia política es de campos de aplicación de sus modelos, en particular, el ascenso de la administración de empresas como una carrera profesional de las más atractivas para los jóvenes estudiantes universitarios. Por otra parte, los estudios políticos adoptan el modelo de la "rational choice" como una adecuación directa a las teorías económicas dominantes. La rela- 
ción de cada disciplina en América Latina con el desarrollo de la misma en otros países y regiones del mundo cambia en la medida en que los conceptos de desarrollo y dependencia constituían un filtro ideológico, un criterio de relevancia, para la recepción de desarrollos científicos que tenían lugar en Estados Unidos o en Europa.

Cada disciplina ha evolucionado individualmente, centrándose en problemáticas propias de la transición de la economía mundial y sus consecuencias.

La ciencia política es un buen ejemplo de evolución desde los problemas multidisciplinarios del desarrollo y la dependencia a problemas estrictamente políticos, en particular, la democracia. Tras la imposición de dictaduras en casi toda América Latina, las discusiones teóricas buscaron definir el tipo de régimen que éstas imponían. Se discutió si pertenecían al tipo fascista o no, y puesto que el calificativo era más útil para la denuncia que para el análisis, ese debate condujo al problema de la concepción de Estado y de ahí surgió la problemática de la relación Estado-sociedad. En este punto, ya las cuestiones del desarrollo y la dependencia estaban fuera del campo en que se discutía, ahora con teorías de filosofía política y sin relación con situaciones históricas particulares. Por ejemplo, el tema de la transición desde regímenes autoritarios originó una literatura que trascendió en sus desarrollos teóricos a la preocupación coyuntural en la que se generó, al mismo tiempo que algunos afirmaban que la ciencia política estaba muerta.

Los ejemplos pueden multiplicarse, pero es necesario definir la situación actual de las ciencias sociales bajo la dominación del paradigma neoliberal. Algunas características ya se han anunciado más arriba y su consideración requiere afirmar que tienen rasgos que representan ventajas para el desarrollo del conocimiento pero que, al mismo tiempo, son también limitaciones para la aparición de perspectivas alternativas. Por una parte, se ha hablado de "pensamiento único" para caracterizar la dominación de la economía liberal y sus derivados, al punto de constituir una suerte de sentido común dominante. Esta aparente uniformidad tiene como consecuencia la dispersión de esfuerzos por conocer lo que parecen problemas aislados y distintos, a pesar de su evidente conexión con la situación de poder actual a todos los niveles. Esta dispersión genera la apariencia de pluralismo sin límites en las distintas disciplinas de ciencias sociales, lo cual no dejaría de ser positivo, aun cuando se desdibujen los límites del recorte en la realidad con que cada ciencia social ha constituido su objeto. Esta situación parece dar la razón a la posición posmoderna que declaraba obsoletos todos los "grandes relatos" o teorías generales. Sin embargo, enfrentar los problemas actuales parece requerir algunas ideas generales que permitan atribuir sentido a los conocimientos parciales y desarticulados que, en el intento de describir racionalmente algunos fenómenos producen 
impresiones paradojales, que deberían conducir a hipótesis que permitieran comprenderlos racionalmente.

Un ejemplo, suficientemente general como para llamar la atención, es el difícil mantenimiento de la vigencia de la legalidad en los estados nacionales como para que sigan siendo la forma predominante de la dominación política en una economía global. Sin mencionar la calificación de Estado fallido, usada con tintes racistas evidentes cuando se trata de países africanos, se puede preguntar por las diversas racionalidades en juego en la migración desde países periféricos a países centrales y la migración entre países periféricos, fenómenos que hacen dudar de la capacidad de los estados involucrados para hacer aplicables sus propias leyes. No hay que decir que los Estados Unidos enfrentan estos problemas al tener dentro de sus fronteras a más de diez millones de inmigrantes ilegales que no sólo ponen en evidencia la incapacidad o falta de voluntad de mantener sus fronteras, sino también la inaplicabilidad de la legislación laboral del país, al permitir la explotación de esos trabajadores en condiciones que hacen rentable el no cumplimiento de las leyes migratorias.

Por otra parte, en Europa se presenta un movimiento doble de integración en la Unión Europea y una demanda de autonomía y federación, cuando no de independencia de regiones que hasta ahora, mal o bien, han sido parte de estados como Reino Unido, Espańa y Francia, para no mencionar a los recientes que han resultado de la disolución de Yugoslavia y de la Unión Soviética. Todo esto ha generado también movimientos migratorios que, dentro de Europa, se suman a la migración extra europea procedente de África principalmente.

Si se resume la situación como crisis de un sistema que produjo la economía más dinámica de la historia —el capitalismo—, que conformó un sistema global, y una forma de organización de la dominación política que dividió el mundo en estados nacionales, los cuales hoy parecen haber encontrado contradicciones entre ambos sistemas que no se presentan como resolubles pacíficamente con los marcos legales existentes, y en tantos niveles que aparentan requerir una nueva conceptualización que permita comprender racionalmente el conjunto de problemas para los que, hasta este momento, sólo existiera el uso de una represión que evidencia la inaplicabilidad de las leyes vigentes dentro de los estados nacionales y en el plano internacional.

Nadie tiene instrumentos de conocimiento para predecir el futuro de la humanidad, más allá de los deseos que se fundan en sus intereses. Sin embargo, eso mismo permite decir que lo que está en crisis y no encuentra una salida previsible es la complejidad de la combinación entre poderes económicos y poderes políticos, en todos los ámbitos y en todos los niveles; eso es lo que esconde la descripción de poderes "fácticos", cada vez más violentos. 


\section{Conclusión}

Los paradigmas que han dominado y orientado el desarrollo de las ciencias sociales latinoamericanas han presentado semejanzas y diferencias que se explican por los cambios del mundo ideológico en el que las mismas se han desenvuelto. Y cabe destacar que si bien han producido un crecimiento notable de disciplinas poco frecuentes en las universidades de la región antes de la Segunda Guerra Mundial -al punto que hoy se celebran congresos masivos de especialistas de estas ciencias-, en lo que respecta a su conexión con proyectos nacionales, no parecen haber tenido los resultados esperados.

El paradigma desarrollista centraba conceptualmente sus ideas en la noción de desarrollo nacional, teniendo como eje un proyecto de industrialización planificado y protegido por el Estado, para lo cual las ciencias sociales contribuían con una visión interdisciplinaria que buscaba conocer y explicar los cambios asociados con el desarrollo de una industria nacional.

Después de más o menos una década de vigencia de estas ideas y programas, las consecuencias políticas e ideológicas de la revolución cubana produjeron una corriente que puso en duda las posibilidades del desarrollo nacional sin una lucha por la independencia económica, dado que los resultados de los esfuerzos industrializadores mostraban resultados insatisfactorios debido a la dominación de nuevas formas de dependencia que, además, desarticulaban internamente las economías, las regiones y la sociedad misma de los países dependientes. Esto ponía en el orden del día la revolución socialista.

En lugar de la revolución, lo que ocurrió fue una contrarrevolución liberal que, en consonancia con lo que ocurría en el resto del mundo, ha impulsado un programa de integración a los cambios globales, con resultados de aumento de la desigualdad, de la pobreza y de la migración.

La visión interdisciplinaria que inauguró el desarrollismo fue mantenida, con diferencias de ejes y énfasis por el dependentismo. Sin embargo, el economicismo neoliberal produjo un fraccionamiento e incluso aislamiento disciplinario al mismo tiempo que desdibujó la orientación dentro de cada ciencia social, produciendo un sano pero poco productivo pluralismo. Esto último no se refiere a la cantidad de información, estudios y reflexiones disponibles hoy en los distintos campos en que actúan las ciencias sociales, sino a la ausencia de una perspectiva que permita siquiera insinuar alternativas a la situación actual y a sus problemas. 


\section{Nota sobre bibliografía}

No se ha querido recargar este texto con referencias más allá de las imprescindibles, en notas al pie. Sin embargo, para caracterizar al paradigma desarrollista, se puede anotar el clásico artículo de Prebisch, "El desarrollo de la América Latina y algunos de sus principales problemas", escrito en 1949 como introducción al Estudio económico de la América Latina de 1948, publicado en múltiples ocasiones. Para el dependentismo se puede anotar el artículo de André Gunder Frank, "El desarrollo del subdesarrollo", también republicado muchas veces, $y$, para el neoliberalismo, el documento de trabajo de Dornbusch y Edwards (citado más arriba) del Banco Mundial.

Recibido el 1 de septiembre de 2014.

Aceptado el 25 de septiembre de 2014. 